\title{
From Anti-China Rhetoric to Anti-Asian Behavior: The Social and Economic Cost of "Kung Flu"
}

Justin Huang ( $\nabla$ huangjt@umich.edu )

University of Michigan Ross School of Business

Masha Krupenkin

Boston College

David Rothschild

Microsoft Research

Julia Lee

Stephen M. Ross School of Business, University of Michigan

Article

Keywords:

Posted Date: February 10th, 2022

DOI: https://doi.org/10.21203/rs.3.rs-1251395/v1

License: (c) (i) This work is licensed under a Creative Commons Attribution 4.0 International License.

Read Full License 


\title{
From Anti-China Rhetoric to Anti-Asian Behavior: The Social and Economic Cost of "Kung Flu"
}

\author{
Justin T. Huang \\ Masha Krupenkin \\ David Rothschild \\ University of Michigan \\ Boston College \\ Microsoft Research \\ Julia Lee Cunningham \\ University of Michigan ${ }^{1}$
}

January, 2022

\footnotetext{
${ }^{1}$ Justin T. Huang is an Assistant Professor of Marketing at the University of Michigan, Masha Krupenkin is an Assistant Professor of Political Science at Boston College, David Rothschild is an Economist at Microsoft Research, and Julia Lee Cunningham is Associate Professor of Management and Organizations. They can be reached at huangjt@umich.edu, krupenki@bc.edu, davidmr@microsoft.com, and profjlee@umich.edu, respectively.
} 


\begin{abstract}
Discrimination and violence directed towards Asian Americans in the United States increased dramatically following the onset of the COVID-19 pandemic. In this paper, we examine consumer discrimination against businesses associated with Asian-Americans. Leveraging the COVID-19 crisis as an exogenous shock to Americans' level of anti-Chinese sentiment, we utilize a series of analyses combining survey data, online search trends, and consumer cellular device mobility data to measure the effects of this shock on consumer discrimination against Chinese and other Asian restaurants. Survey and search data show that attitudes towards Chinese and non-Chinese Asian food declined precipitously during the COVID-19 crisis, and this change in attitudes was driven by a mix of assigning blame for COVID-19 spread to Asians and experiencing fear of Chinese food. Analysis of cellular phone mobility data shows Asian restaurants suffered a $18.4 \%$ drop (95\% C.I.: $-15.9 \%$ to $-20.8 \%$ ) in traffic relative to non-Asian restaurants in the pandemic period. We explore heterogeneity in these effects by political affiliation and find strong correlation between support of former President Trump and avoidance of Asian restaurants. The results are consistent with the role of outgroup homogeneity and ethnic misidentification as drivers of spillover effects of anti-Chinese sentiment on non-Chinese Asian restaurant traffic. This work documents some of the unique economic challenges faced by Asian Americans during the COVID-19 pandemic and has substantial implications for the study of consumer discrimination and stigmatization in public health communications.
\end{abstract}




\section{Introduction}

Scholars have long documented patterns of labor discrimination against people of color in the U.S. (Bertrand and Mullainathan 2004; Pager 2003; Kuppuswamy and Younkin 2020; Acquisti and Fong 2020; Chavez 2021; Broyles and Fenner 2010). These forms of discrimination have substantial negative impacts on communities of color, denying social mobility to historically marginalized groups (Bassanini and Saint-Martin 2008; Dustmann and Theodoropoulos 2010; Ghazaryan 2019). Even as some forms of discrimination have decreased over the recent decades (Quillian, Lee and Honoré 2020), racial discrimination in labor markets remains stubbornly persistent (Mason et al. 2005; Quillian et al. 2017). In this paper, we examine a closely related but much less studied economic phenomenon - consumer discrimination against businesses, especially small businesses associated with Asian Americans during the COVID-19 pandemic.

Historically, marginalized groups have responded to the challenges of labor discrimination by starting their own businesses providing unique goods and services. Many Asian immigrants to the United States achieved economic success using this model by starting businesses such as laundromats and ethnic restaurants (Liu 2015). In the late 19th century, the U.S. heavily encouraged Asian immigration to supply cheap labor for manufacturing their burgeoning railroad system (White 2011). These immigrants founded America's first Chinese restaurants. By the early 20th century, both hostility towards Chinese immigrants and Americans' appetite for Americanized Chinese food had increased substantially (Liu 2015). The 1970's saw a further resurgence of American interest in "authentic" Chinese food (Liu 2015). While restaurant entrepreneurship remains a pathway to economic success for Asian Americans, discrimination by consumers can negatively impact the efficacy of this pathway, especially during periods of heightened anti-Asian sentiment.

Marginalization, stigmatization, and even violence towards minority groups has been a frequent historical response to public health (McCauley, Minsky and Viswanath 2013), terrorism 
(Chandrasekhar 2003), and economic (Johnson 1996) events. While public blame (i.e., rhetoric from politicians and mainstream media) is typically directed towards a singular foreign group, domestic hate crimes in response to these events often scapegoat American minorities and related groups that are mistakenly targeted. Tragically, Balbir Singh Sodhi, a Sikh American, was murdered after being mistaken for Arab Muslim in the aftermath of the 9/11 attacks, and Vincent Chin, a Chinese American, was murdered after being mistaken for Japanese amidst rising blue collar unemployment and American-Japanese economic competition in the early 1980s. Research on out-group homogeneity bias (Quattrone and Jones 1980) suggested that people tend to view out-group members as more similar to one another, as opposed to in-group members. Adding to this bias, scholars have identified a cross-race effect, which is the tendency to recognize faces that belong to one's own racial group while having difficulty differentiating members of the cross-racial group (Chance and Goldstein 1981; Lebrecht et al. 2009). Further, individuals with less cross-race exposure are more likely to harbor prejudicial attitudes towards other groups (Bursztyn et al. 2021; Zebrowitz, White and Wieneke 2008). Taken together, these effects can allow prejudicial attitudes towards an out-group (Asian Americans, in our case) to drive prejudicial actions directed towards domestic minority groups.

In this paper, we examine the role of consumer discrimination against Asian restaurants in the United States in the context of the COVID-19 pandemic. Previous studies have found that consumer discrimination substantially decreases small business ownership and self-employment among people of color in the U.S. (Borjas and Bronars 1989; Fairlie 1999; Holzer and Ihlanfeldt 1998; Liu, Liao and Ming 2020), as does discrimination by funding sources (Younkin and Kuppuswamy 2018). Consumer discrimination is likely to be especially salient for restaurants that specialize in ethnic cuisines, as the food's ethnic origin is a key aspect of product differentiation. We leverage the COVID-19 pandemic as an exogenous shock to rhetoric and attitudes about Asian Americans in the U.S. Soon after COVID-19 began spreading in the U.S., then-President Trump and the Republican Party began a concerted effort to blame China for the virus. Political and media figures used the phrases "China virus" and "Kung flu" to de- 
scribe the coronavirus, in contradiction to World Health Organization (WHO) guidance (World Health Organization 2015) and prior research demonstrating how disease naming can lead to stigmatization, particularly of marginalized and minority groups (Perry and Donini-Lenhoff 2010; McCauley, Minsky and Viswanath 2013; Keusch, Wilentz and Kleinman 2006). The effects of this rhetoric did not go unnoticed - the number of anti-Asian hate crimes spiked during the pandemic (Gover, Harper and Langton 2020; Tessler, Choi and Kao 2020), impacting both Chinese Americans and the broader Asian American community. Anti-Chinese rhetoric caused a spike in anti-Asian sentiment within the broader population, leading to consumer discrimination against Asian restaurants in the U.S., with substantial financial cost incurred by Asian-owned businesses.

Using web search, survey, and movement data, we document the impact of anti-China sentiment on both Chinese Americans and spillover effects on other Asian American populations. First, we use web search data to demonstrate the exogenous shock of the COVID-19 pandemic on American conceptions of China and Chinese food. Next, movement data allows us to measure the effect of anti-Asian attitudinal shifts on consumer discrimination against both Chinese and other Asian restaurants, quantifying the economic effect of anti-Chinese rhetoric on Asian American communities. Finally, we use survey data to explore different underlying mechanisms that influence these shifts.

We find clear evidence of sharp attitudinal shifts against China, Chinese Americans, and Asian Americans as a whole during the COVID-19 pandemic. These shifts have real economic consequences for Asian American communities, as people who have internalized this rhetoric have heightened concerns over the safety of Chinese products, most prominently Chinese restaurants. Furthermore, many Americans are not good at differentiating between Chinese Americans and other East Asian Americans, putting the larger Asian American community at risk from anti-Chinese sentiment and behavior. It is not surprising that we find an early and disproportionate drop in business suffered by Chinese restaurants during the COVID-19 
crisis, but also for other non-Chinese Asian American restaurants, suggesting that the increase in anti-China sentiment incurred not only a social cost for Asian Americans at large, but it also incurred a real economic cost.

Our contributions are three-fold. First, we examine the role of current events in shaping levels of consumer discrimination against businesses associated with a specific ethnic group. In some cases, entrepreneurship has historically served as a viable exit strategy for populations facing labor discrimination. However, for businesses serving customers outside its ethnic community of origin, consumer discrimination can hamper the businesses' economic viability. If levels of consumer discrimination fluctuate based on current events, otherwise profitable businesses may quickly become unviable during periods of high discrimination and violence ${ }^{1}$. Furthermore, unpredictability of demand for the businesses' products may also serve as a barrier to entry for potential entrepreneurs. If a Chinese restaurant will be doomed by a chance upswell in anti-Asian sentiment at some point in the future, why open a Chinese restaurant?

Second, we explore the fallout from recent shifts in sentiment towards Asian Americans. Recent research has documented the rise of racial discrimination and prejudice against Asians and Asian Americans in the U.S. during the course of pandemic, which resulted in poorer mental and physical health (Lee and Waters 2020) and marginalization (Li and Nicholson Jr. 2021) in these groups. Our research documents the far-reaching behavioral consequences of negative attitudes against Asian Americans in the context of consumer discrimination.

Finally, our study contributes to the psychological theories of collective blame by highlighting the role of ethnic misclassification in consumer discrimination. By examining the costs incurred on both Chinese and non-Chinese Asian restaurants, we capture the process of blame spillover from businesses associated with one ethnic group to the larger tangentially-related populations. This spillover effect, at least partly fueled by the "yellow peril" stereotype for Asians in general (Tessler, Choi and Kao 2020) lends support to the theory of collective blame

\footnotetext{
${ }^{1}$ https://www.pbs.org/newshour/economy/asian-owned-businesses-say-theyre-reeling-from-hate-and-violenceoperating-in-fear
} 
(Denson et al. 2006; Lickel et al. 2006; Stenstrom et al. 2008) that arises from out-group homogeneity bias and cross-race effects. To the best of our knowledge, our study is first in examining these spillover effects via ethnic misclassification in the context of consumer discrimination in an ecologically valid setting. For instance, cross-race effects have been found in people's perception of out-group members' faces. Our research extends this line of work by showing that a similar pattern occurs with consumer perception of out-group-owned businesses as well. Studying consumer discrimination based in ethnic and racial misclassification also advances our understanding the experiences of individuals and entities that are regularly misclassified. For instance, research on racial misclassification (Campbell and Troyer 2007) found the negative psychological consequences for American Indians who were often misclassified for a different racial group. Our research stresses the prominence of a similar mechanism for Asians who are not ethnically Chinese, and broadens it to encompass social and economic costs. Understanding the role of ethnic misclassification in discrimination allows us to better understand the cognitive processes behind discriminatory behavior.

The rest of the paper is organized as follows. Section 2 focuses on background and theoretical perspectives that inform our hypotheses for study. Section 3 describes our data sources. Section 4 describes our methodology and results. We confirm the role of the COVID-19 pandemic as an exogenous shock to anti-Asian sentiment and highlight the unique effect of this shock on Chinese and other Asian restaurants. We identify fear of Chinese food safety, blame of Asian Americans for COVID-19, and ethnic misclassification of restaurants as possible psychological mechanisms for this effect. The fifth and final section describes our conclusions and suggests further directions for this research. 


\section{Background}

Innuendos of "uncleanness" and disease have long been used to stigmatize marginalized populations and justify their expulsion. From blaming European Jews for the Bubonic Plague in the Middle Ages (Jedwab, Johnson and Koyama 2019) to claiming that immigrants crossing the United States' southern border are 'diseased'2, majority groups have long misattributed blame for diseases to "undesirable" minority populations. In the U.S., portrayal of immigrants as dangerous and diseased shaped immigration policy for decades (Kraut 1995; Markel and Stern 1999). Modern-day attitudes towards disease threat are closely related to anti-immigration attitudes (Green et al. 2010; Krings et al. 2012). This carries forward into the present with rhetoric falsely trying to tie the fourth wave of COVID-19 illness to undocumented immigrants coming through the U.S.' southern border ${ }^{3}$

These stigmas have been especially prevalent in the treatment of Asian Americans in the 19th and 20th centuries. Medical examinations of Chinese immigrants arriving at Angel Island were frequently harsher than those of Europeans at Ellis Island, and the rejection rate for Chinese immigrants was at least five times higher than for immigrants at Ellis island (Markel and Stern 1999). These attitudes extended towards Asian cultural products in the U.S., especially Chinese food. While early Chinese restaurants founded in San Francisco during the California Gold Rush were praised as tasty and economical, the rising tide of Sinophobia soon led to rumors of the consumption of rats and snakes as Chinese delicacies, leading to a decline in Chinese restaurant popularity ( $\mathrm{Liu} 2015)$. More recently, the popularization of the term "Chinese Restaurant Syndrome", based in medically-unfounded fears over the effects of Monosodium Glutamate (MSG) (Wahlstedt et al. 2021; Mosby 2009), is another example of cultural discrimination against Chinese restaurants.

Portrayals of the COVID-19 crisis echoed many of these historical patterns of negative at-

\footnotetext{
${ }^{2}$ https://www.splcenter.org/hatewatch/2020/04/21/anti-immigrant-movement-has-history-politicizing-disease

${ }^{3}$ https://www.msn.com/en-us/news/politics/politifact-declares-desantis-e2-80-99-claims-covid-rise-is-due-toillegal-border-crossings-is-e2-80-98false-e2-80-99/ar-AAN1TqS?ocid=uxbndlbing
} 
titudes and discrimination against this group in the face of public health concerns. The COVID19 virus was regularly referred to as the "Chinese virus" or "China virus", both offline (MastersWaage, Jha and Reb 2020) and online (Budhwani and Sun 2020; Ziems et al. 2020; Hswen et al. 2021). Donald Trump and Trump-supporting Republicans and media began to refer to COVID-19 as the "China virus" and explicitly blame the pandemic on China despite consistent criticism from Asian Americans and left-leaning media outlets. Between March 16, 2020 and Jan 3, 2021, Trump used the phrase "China virus" or "Chinese virus" in 54 separate tweets. This explicit blame on China by the politicians was then reinforced and further spread into the mainstream media outlets that rebroadcast this rhetoric. Recent research has demonstrated how social media also plays a vital role in building and reproducing negative sentiment against marginalized groups. For example, recent studies have examined the spread of anti-Muslim sentiment through hashtags on Twitter (Miro-Llinares and Rodriguez-Sala 2016; Müller and Schwarz 2021). Similarly, two studies to date have demonstrated the link between hashtags that used the language of this rhetoric (\#Chinesevirus, for instance) and anti-Asian sentiments on Twitter (Hswen et al. 2021; Pei and Mehta 2020). Although establishing a causal relationship between the political rhetoric and anti-Asian sentiment is beyond the scope of our current research, this suggests a possibility that anti-Asian sentiment initiated by the political figures may have spread broadly and quickly on both mainstream media and social media.

Against this backdrop, latest research adds to the growing evidence for the Asian Americans blamed for the COVID-19 pandemic. For instance, Reny and Barreto (2020) finds that among Americans, fear of COVID-19 is highly correlated with anti-Asian attitudes and support for anti-Asian immigration policies. Furthermore, an experimental study has shown that emphasizing the origin of COVID-19 to China increased anti-Asian sentiment and xenophobia (Dhanani and Franz 2021). Following this logic, we argue that the COVID-19 pandemic served as an exogenous shock that gave voice to politicians who were increasingly making explicitly racial appeals by singling out marginalized groups (Stephens-Dougan 2020), thereby contributing to the rise of anti-Asian attitudes within the U.S. 
Drawing from the psychological theory of blame, we put forth the idea that not only was the country of origin directly blamed for the pandemic, but so were other groups often mislabeled as Chinese that subsequently became the targets of collective blame. Alicke's (2000) model of culpable control suggests that blame is the outcome of psychological processes driven by cognitive and motivational biases, which may be independent of a party's actual liability (Alicke 2000; Hart and Honoré 1985; Prosser and Wade 1971). Further, his theory posits that people may assign blame based on the proximity criteria. To the extent that the associated party is viewed as sufficiently proximate to the party that is presumed to be guilty, it is possible that even the group (i.e., businesses owned by Chinese Americans) that is not blamed for the harm may still be cognitively implicated. While there were legitimate questions about whether or not food could carry COVID-19 in the early days of the pandemic, this concern alone would not be sufficient if some restaurants were disproportionately affected by the COVID19 pandemic than others, as there was not a legitimate concern about any particular type of food. Facing COVID-19 as an exogenous shock and the anti-Asian rhetoric and attitudes that followed, we hypothesize that:

\section{H1: During the COVID-19 crisis, Chinese restaurants will see a substantial drop in visits} relative to non-Asian restaurants.

Much of the consumer research on blame spillover has been documented in the context of brands that were implicated in moral transgressions. This effect is found to be more prominent to the brands consumers identify as similar to the brand that was implicated in ethical scandal (Borah and Tellis 2016; Paruchuri and Misangyi 2015; Trump and Newman 2017). Based on this literature, we further argue that how consumers ascribe blame on the associated groups may contribute to the struggles of other Asian restaurants that are not Chinese. This blame spillover may occur via two channels. First, it is possible that non-Chinese entities were incorrectly identified as Chinese, thereby being erroneously blamed for the pandemic. Second, it is also plausible that non-Chinese entities were correctly identified (which we call "eth- 
nic misidentification hypothesis" detailed below), but viewed as a proximate entity under the broader umbrella of Asian race and ethnicity, thereby being categorically avoided. Both possibilities support the idea that other Asian restaurants will be negatively affected at the early onset of COVID-19 in the U.S., leading to our second Hypothesis:

\section{H2: After COVID-19, non-Chinese Asian restaurants will also experience a substantial} drop in visits relative to non-Asian restaurants.

Of note, these portrayals were not spread evenly across the population - Republican leaning news outlets, such as Fox News, were more likely to blame China for the pandemic than were other outlets (Krupenkin et al. 2021). Due to the prevalence of these narratives among Republican politicians and news sources, we argue that this shock was not homogeneously distributed throughout the population. Scholars have long noted that partisans in the U.S. tend to follow opinion cues provided by leaders of their political party (Druckman 2001; Lenz 2013; Bullock 2020). Partisans are much more likely to follow suggestions and absorb information when it is presented to them by leaders in their own party, as compared to non-partisan figures and especially figures from the opposing party. This partisan cuing effect extends to a variety of topics, including vaccination (Weisel 2021), mask-wearing (Milosh et al. 2020), and COVID-19 blame attribution (Graham and Singh 2021). This suggests that Republicans, whose party leaders and media outlets engaged in anti-Asian cuing behavior, should be more likely to respond with consumer discrimination against Chinese and Asian restaurants, leading to Hypothesis 3:

\section{H3: Areas with more Trump support would see a larger relative drop in Chinese restau-} rant visits than areas with lower Trump support.

Finally, we propose a potential mechanism for spillovers to non-Chinese Asian restaurants (such as "Tiger Belly Noodle Bar") whose names are ethnically ambiguous but could potentially be classified as Chinese. During the pandemic, anti-China rhetoric often invoked preju- 
dice and stereotypes such as the eating of bats or snakes $4^{4}$ and martial arts 5 , which, while targeted at China, are common stereotypes of East Asians as a whole. Politicians' usage of these stereotypes could both activate in-group favoritism and be indicative of the prevalence of these out-group stereotypes among their constituents. In either case, an activation of group membership has been shown to change how individuals process and perceive information about the out-group members, with the potential to increase perceived out-group homogeneity (Ostrom et al. 1993; Mullen and $\mathrm{Hu}$ 1989; Krosch et al. 2013). We thus predict that Trump voters who are more exposed to anti-China rhetoric from Republican leaning news outlets will exhibit decreased differentiation between Asian ethnic groups and thereby increased chances of misidentification. This yields our final hypothesis:

H4: Trump voters would be more likely to misidentify non-Chinese Asian restaurants than non-Trump voters.

We explore these hypotheses within consumer mobility data by comparing pre- and postpandemic consumption behavior, supplementing our analysis with search data and a series of surveys to describe linkages between political rhetoric, sentiment, search, and subsequent behavior.

\section{Data}

We use four main data sources to determine the relationship between COVID-related antiAsian sentiment and consumer discrimination against restaurants. Table 1 summarizes these data sources.

First, we used the web search data from Google to highlight the nature of the exogenous shock to American conceptions of China and Chinese food during COVID-19. Next, we use

\footnotetext{
${ }^{4}$ https://www.washingtonpost.com/nation/2020/03/19/coronavirus-china-cornyn-blame/

${ }^{5}$ https://www.bbc.com/news/av/world-us-canada-53173436
} 
Table 1: Data Summary

\begin{tabular}{lll}
\hline Dataset & Measure & Dates \\
\hline Google Trends & Anti-Asian Attitudes and Food Safety & $1 / 16-8 / 20$ \\
SafeGraph Mobility Data & Visits to Restaurants & $11 / 4 / 2019-6 / 7 / 2020$ \\
Pollfish Survey Data & Anti-Asian Attitudes & Fielded 5/5/20,8/27/20, \\
& & $10 / 29 / 20,4 / 15 / 21$ \\
Confusion Survey Data & Restaurant Ethnic Misidentification & Fielded 3/27/21-5/8/21
\end{tabular}

movement data provided by SafeGraph to directly measure consumer discrimination in the form of visits to Chinese restaurants, other Asian restaurants, and non-Asian restaurants. We then turn to understanding the underlying psychological mechanisms behind these forms of discrimination. We gathered survey data from 4,000 Americans (in four waves) to determine whether they blamed Chinese and other Asian American populations for COVID-19, and how this blame related to their beliefs about Chinese food safety. Finally, we use a survey with virtual workers to understand whether the spillover effects were driven by ethnic misidentification of other Asian restaurants as Chinese restaurants.

\section{Search Data}

We use weekly search data from Google Trends in order to measure the effect of the COVID19 pandemic as an exogenous shock to anti-Asian sentiment during 2020. Google Trends data has been shown to be a powerful measure of racial animus (Stephens-Davidowitz 2014) that correlates strongly with a wide variety of outcomes, including electoral (Stephens-Davidowitz 2014) and health outcomes (Chae et al. 2015).

Table 2 describes the search queries that we examine. We use search data for two main purposes. The first is to establish the temporal relationship between the COVID-19 pandemic 
and anti-Asian attitudes. Search data is uniquely well-suited for this purpose, as it measures organic increases in collective attention to a specific topic. To do this, we examine anti-Asian web searches that are not directly related to COVID-19. The reason is that while it is unsurprising that searches that tie COVID-19 to China would spike during the pandemic (so a search for "china virus" would not necessarily tell us anything about the searcher's attitudes), searches for something like "china owns us" would be more indicative, since they have no clear relationship to the pandemic.

We look at several categories of anti-China searches: searches relating to China and Communism (political), searches relating to China and debt (economic), and searches relating to explicit anti-China phrases (social/stereotypical). All three of these categories are related to negative attitudes towards China and stereotypes about Chinese people and culture that predate the pandemic. We also compare searches for Chinese consumption of bats versus consumption of dogs. Search interest in Chinese bat consumption was likely driven by media coverage, but consumption of dogs has no relationship to the pandemic and did not receive media coverage. As such, if we see an increase in searches for Chinese consumption of dogs, this is another possible indicator of affirming the negative stereotypes about China.

The second purpose of using search data is to determine whether Americans treated food from Chinese restaurants differently during the pandemic than restaurant food in general. If anti-Chinese sentiment affected Chinese restaurants specifically (in terms of drop in customer visits), we should see different patterns in searches about Chinese food than about other restaurant food, supporting Hypothesis 1.

We examine these queries on the weekly level from 2016-2020. While there is occasional seasonality within search data (for example, people showing special interest in Chinese food on Christmas Day), comparing searches over the course of five years eliminates the possibility that any patterns we see in 2020 are the result of seasonal fluctuations. 
Table 2: Google Trends Search Queries

\begin{tabular}{|c|c|c|}
\hline Category & Type & Google Trends Query \\
\hline Anti-China & Communism & china communist + chinese communist + china $c c p+$ chinese $c c p$ \\
\hline Anti-China & Debt & china debt + chinese debt + china owns + owe china \\
\hline Anti-China & Explicit & fuck china + boycott china + china sucks \\
\hline Anti-China & Eating Bats & china eat bat + china eat bats + chinese eat bat + chinese eat bats \\
\hline Anti-China & Eating Dogs & china eat $\operatorname{dog}+$ china eat $\operatorname{dog} s+$ chinese eat $\operatorname{dog}+$ chinese eat $\operatorname{dog} s$ \\
\hline Food Safety & Restaurant Safety & food safe + takeout safe + restaurant safe + delivery safe \\
\hline Food Safety & $\begin{array}{l}\text { Chinese Restaurant } \\
\text { Safety }\end{array}$ & $\begin{array}{l}\text { chinese food safe }+ \text { chinese takeout safe }+ \text { chinese restaurant safe } \\
+ \text { chinese delivery safe }\end{array}$ \\
\hline
\end{tabular}

\section{Mobility Data}

We analyze consumer mobility data from the firm SafeGraph. SafeGraph captured mobile device location data from over 40 million devices from the period November 4, 2019 through June 7, 2020. This mobile device location data is combined with labels defining the perimeters of approximately 5 million Points of Interest (POI) across the U.S. to generate weekly aggregated counts of visitors to each POI. We filter the week-POI aggregated visit counts to isolate data from 381,692 unique restaurant locations. We focus on restaurants specifically due to their ubiquity, ease of affiliation between the business and a particular ethnic group, the rise of food safety-related searches following COVID-19, and historical and contemporary usage of food stereotypes as an outlet for xenophobic sentiment. We conduct our analysis within a difference-in-difference framework, measuring the differential impact of the onset of COVID19 on visits to Asian versus non-Asian restaurants. This analysis controls for persistent differences in traffic for each restaurant and common temporal shocks. 


\section{Attitudinal Survey Data}

We ran two samples of 1,000 respondents for the same set of questions conducted on May 5 and August 27, 2020 (noted as Survey 1), and slightly updated version on October 29, 2020 (Survey 2). We ran a final survey, also 1,000 respondents, on April 15, 2021 (Survey 3). The multi-waves were designed to capture the trends in our core questions of sentiment and behavior as the pandemic progressed. Surveys were conducted within native advertising units in a mix of mobile applications on both iOS and Android, and in both mobile and desktop web experiences, using the Pollfish interface and delivery mechanism. Participants were at least 18 years old, and randomly selected from the pool of eligible respondents. We asked a total of 25 questions in Survey 1 and 18 questions in Surveys 2 and 3 (see Appendix for a full list of questions that involved both exploratory questions as well as specific questions to be used in this paper). All survey results in the paper are raked to reflect national Census estimates of key demographics.

\section{Restaurant Confusion Survey Data}

We ran a separate study from March 26, 2021 through May 8, 2021 to examine in more depth the degree to which individuals distinguish between various Asian restaurants. 2,000 American participants who were eligible to vote in 2016 and 2020 were recruited through Amazon Mechanical Turk (MTurk). The 2,000 restaurants in the pool were chosen in a stratified random sampling from amongst mono-ethnic restaurants in the SafeGraph dataset. Each participant was asked to classify a randomly-selected set of 20 restaurants based on name alone from a pool of 2,000 real restaurants. Our stratification was chosen to balance between the most common ethnic restaurant cuisines while oversampling Chinese restaurants since they were the focus of messaging and food safety concerns. The sample included 400 Chinese restaurants and 200 each of French, Indian, Italian, Japanese, Korean, Mexican, Thai, and Vietnamese restau- 
rants. Participants were also asked to self-report their gender, age, ethnicity, and voting preferences in both the 2016 and 2020 American presidential election.

\section{Methodology and Results}

\section{Web Searches Confirm Exogenous Shock to Anti-Asian Sentiment}

To examine the temporal shifts in the level of anti-Asian sentiment around the COVID-19 pandemic, we turn to the Google search data. Figure 1 presents the results of the first set of antiChina searches, which focus on non-COVID related anti-China sentiment. In all three cases, search patterns in 2020 looked very different from search patterns in the four years prior. For searches around debt and explicit anti-China searches, we see a sharp discontinuity at the week

of March 11, 2020 that was not present in any of the prior years $]^{6}$ In the case of Communism searchers, we see a slightly subtler effect, where the overall number of searches for China and Communism was substantially higher throughout the year, beginning in mid-March.

Searches related to eating animals, presented in Figure 2, further underscore these results. While there were clear, news-driven spikes for eating bats around the emergence of COVID-19 and again at the beginning of the pandemic in the U.S., the relationship between searches for eating bats and eating dogs is very clear and distinct. Dog-eating behavior had no relationship to the pandemic, but is closely related to anti-Chinese stereotypes.

These search patterns show a sharp discontinuity in anti-Chinese sentiment during the COVID-19 pandemic. Next, we will consider the impacts of this shift in sentiment on the livelihoods of Asian Americans in the U.S.

\footnotetext{
${ }^{6}$ This is despite the U.S. starting a well-covered trade war with China in 2019.
} 

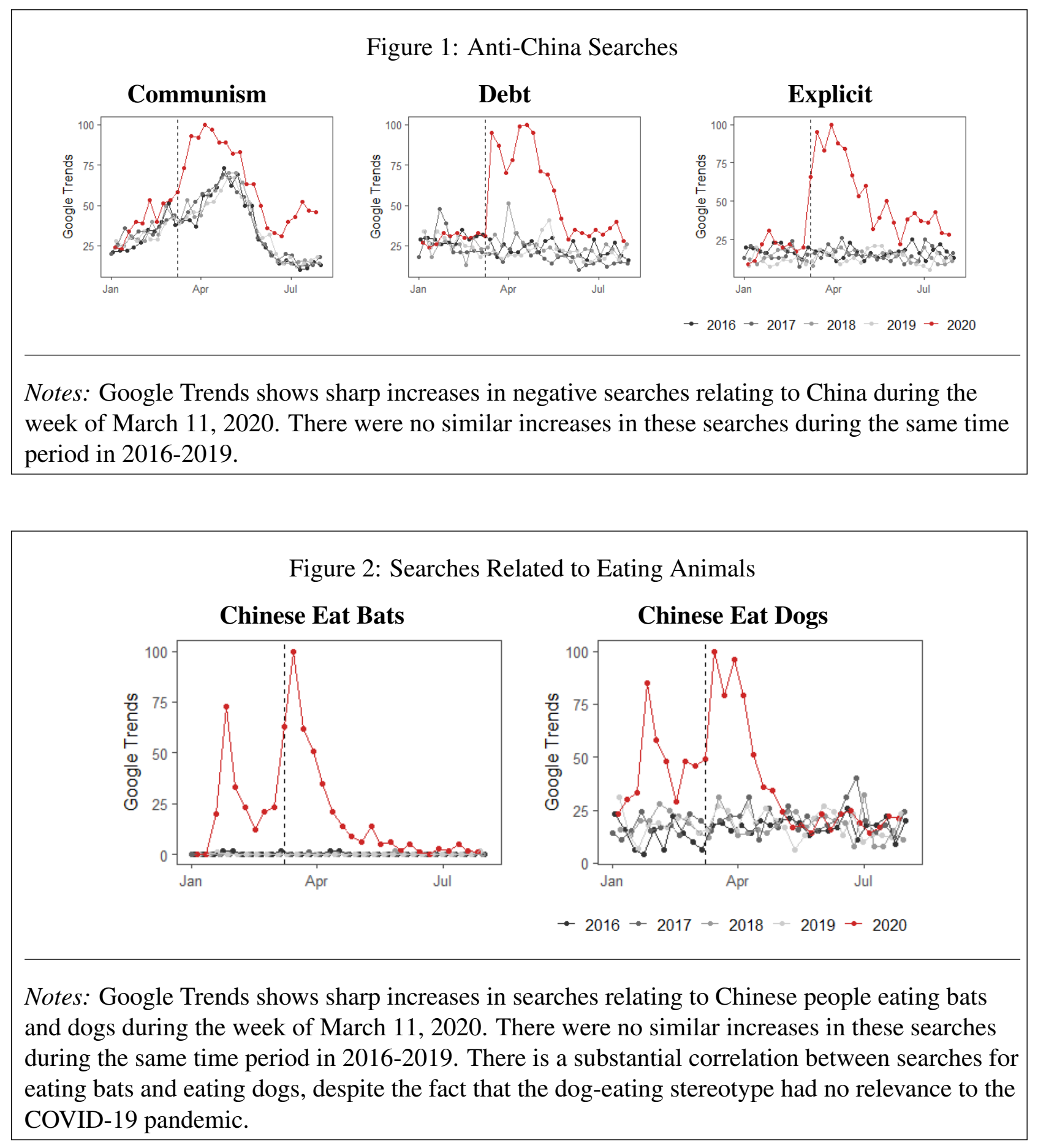

\section{Asian Restaurants Experience Relative Drop in Visits During Pandemic}

We analyze mobile device location data to document the direct impact of anti-China and antiAsian sentiment on traffic to Asian American businesses in the post-pandemic period. This 


\begin{tabular}{|c|c|c|c|}
\hline & \multicolumn{3}{|c|}{ Dependent variable: } \\
\hline & \multicolumn{3}{|c|}{ log_visits } \\
\hline & $(1)$ & $(2)$ & (3) \\
\hline isAsian $x$ postCOVID & $\begin{array}{c}-0.203^{* * *} \\
(0.015)\end{array}$ & & \\
\hline isChinesex postCOVID & \multicolumn{3}{|c|}{$\begin{array}{c}-0.115^{* * *} \\
(0.014)\end{array}$} \\
\hline isNonChineseAsian $x$ postCOVID & & & $\begin{array}{c}-0.2879^{* * *} \\
(0.0197)\end{array}$ \\
\hline Case Rate & $\begin{array}{c}-7.224^{* * *} \\
(1.383)\end{array}$ & $\begin{array}{c}-7.500^{* * *} \\
(1.395)\end{array}$ & $\begin{array}{c}-7.703^{* * *} \\
(1.455)\end{array}$ \\
\hline Week Fixed Effects & Yes & Yes & Yes \\
\hline Restaurant Fixed Effects & Yes & Yes & Yes \\
\hline Observations & $11,086,220$ & $10,256,567$ & $10,294,852$ \\
\hline $\mathrm{R}^{2}$ & 0.837 & 0.837 & 0.837 \\
\hline Adjusted $\mathrm{R}^{2}$ & 0.831 & 0.832 & 0.832 \\
\hline \multirow[t]{2}{*}{ Residual Std. Error } & $0.448(\mathrm{df}=10728568)$ & $0.448(\mathrm{df}=9925678)$ & $0.449(\mathrm{df}=9962728)$ \\
\hline & & ${ }^{*} \mathrm{p}<0$ & $;^{* *} \mathrm{p}<0.05 ;{ }^{* * *} \mathrm{p}<0.01$ \\
\hline \multicolumn{4}{|c|}{$\begin{array}{l}\text { Notes: Results of a difference-in-difference regression examining the relative drop in traffic for } \\
\text { Asian versus non-Asian restaurants in the post-pandemic period. Week and restaurant fixed } \\
\text { effects are utilized to account for parallel time trends and group membership, respectively. } \\
\text { Robust standard errors are clustered on the week and restaurant level. Models (2) and (3) exclude } \\
\text { non-Chinese Asian and Chinese restaurants, respectively, to ensure the comparison group is } \\
\text { always non-Asian restaurants. Results show a significant drop in traffic for Asian, Chinese, or } \\
\text { non-Chinese Asian restaurants in the post-pandemic period relative to non-Asian restaurants. }\end{array}$} \\
\hline
\end{tabular}

naturally lends itself to a difference-in-difference specification to capture the differential impact of the pandemic on traffic to Asian versus non-Asian restaurants. Specifically, we utilize the following equation:

$$
\operatorname{logVisits}_{i t}=\beta_{1} \cdot I\left(\text { Asian }_{i} \times \text { postCOVID }_{t}\right)+\beta_{2} \cdot \text { caseRate }_{j t}+\eta_{i}+\delta_{t}+\varepsilon_{i t}
$$


In this model, $i$ indexes restaurant locations and $t$ indexes the weeks from November 4 , 2019 through June 7, 2020. $\log$ Visits $_{i t}$ is the natural $\log$ of the visit count to restaurant $i$ in week $t$, and caseRate $_{j t}$ is the number of per capita reported cases of COVID-19 in week $t$ for the ZIP Code $j$ containing the restaurant $i$. Our difference-in-difference measure of interest is $\beta_{1}$, which captures the interaction between whether the restaurant $i$ is classified as an Asian restaurant and whether the time $t$ is after March 13, 2020, the major onset of COVID-19 in the United States and declaration of National Emergency. $\eta_{i}$ denote restaurant-level fixed effects capturing persistent differences in traffic for each restaurant location. These $\eta_{i}$ collectively capture differences between Asian and non-Asian restaurants, and thus replace the need for an indicator on Asian restaurants in the typical difference-in-difference specification. $\delta_{t}$ capture common temporal shocks to traffic, such as if outdoor dining restrictions impacted all restaurants post-COVID or there was a reduction in traffic due to national holiday. As additional robustness, we also estimate models with state- and ZIP Code level fixed effects replacing restaurant fixed effects and state-week level fixed effects, which can capture regional variation in the onset and severity in COVID-19.

These results are summarized in Table 3. This analysis shows that in the period after the onset of COVID-19, Asian restaurant traffic dropped a substantial 18.4\% (p<.001, 95\% CI: $-15.9 \%$ to $-20.8 \%$ ) relative to non-Asian restaurant traffic in the same period and after controlling for COVID-19 case rates. Chinese restaurant traffic dropped $10.9 \%(\mathrm{p}<.001,95 \%$ CI: $-8.4 \%$ to $-13.3 \%$ ), while non-Chinese Asian restaurant traffic dropped an even larger $25.0 \%$ $(\mathrm{p}<.001,95 \%$ CI: $-22.1 \%$ to $-27.9 \%)$. These findings provide strong support for Hypotheses 1 and 2, which predicted both Chinese and non-Chinese Asian restaurants would experience substantial drops in visits relative to other types of restaurants. 
Figure 3: ZIP Code level Heterogeneity in Effects by Trump Vote Share
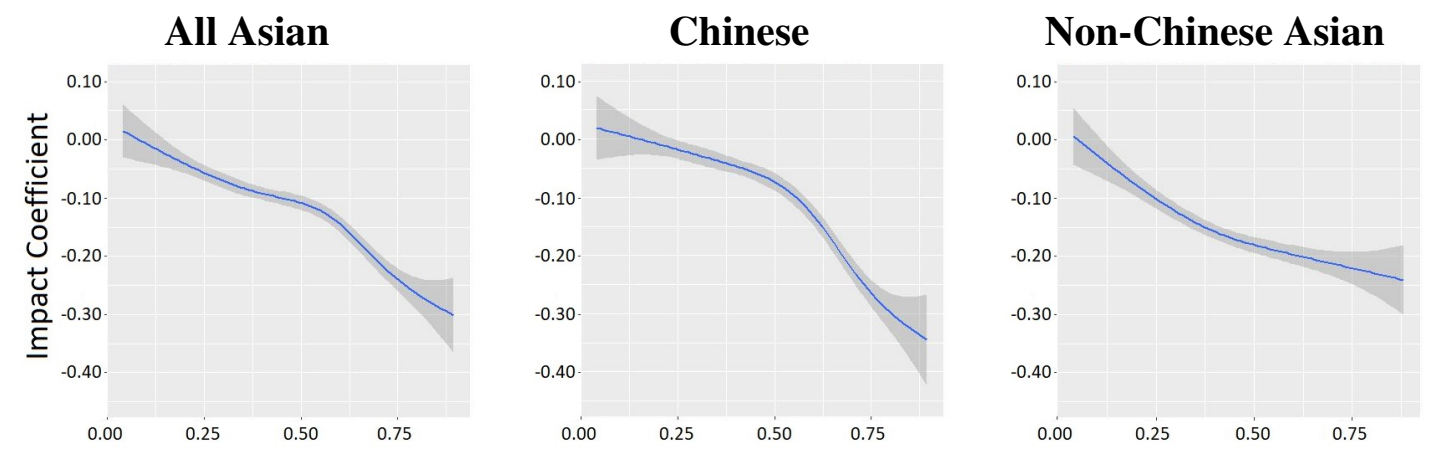

Trump Vote Share (2016)

Notes: ZIP Code level impact to Asian, Chinese, and non-Chinese Asian restaurants, respectively, by Trump voting share in 2016. Impact coefficients are calculated for each ZIP Code via difference-in-difference using the specification in Equation 1 relative to non-Asian restaurants within the ZIP Code. The grey shaded region displays the $95 \%$ confidence interval of the mean impact coefficient (blue line) of ZIP Codes with the given level of Trump support, visualized using LOESS smoothing with span $=0.5$. These plots indicate that Trump voting share in 2016 correlates with greater avoidance of Asian, Chinese, and non-Chinese Asian restaurants in the post-pandemic period.

\section{Greater Trump Support Associated with Larger Drop in Asian Restaurant}

\section{Traffic}

Given that President Trump was a main vector of anti-China rhetoric assigning pandemic blame to China, we look to examine whether greater support for Trump was associated with a larger relative drop in Chinese and more broadly Asian restaurant traffic in the post-pandemic period. For this analysis, we utilize Trump's 2016 voting share rather than his 2020 voting share, as his share in 2020 may have been impacted by both regional variation in pandemic severity and perceptions of his management of the pandemic. We explore heterogeneity in Asian restaurant avoidance by repeating our main analysis at the ZIP Code level, calculating the aforementioned difference-in-difference interaction effects for 1) all Asian restaurants, 2) Chinese restaurants, and 3) non-Chinese Asian restaurants, with results visualized in Figure 3, and interaction regression results reported in Table 4. The ZIP Code level subsamples replicate our 
main effects, indicating persistent negative effects of the pandemic on Asian restaurants. Further, there is a visible negative correlation between traffic and Trump's 2016 voting share at the ZIP Code level. This interaction is significant for each of Asian, Chinese, and non-Chinese Asian restaurants $(\mathrm{p}<.01)$ as shown in Table 4 , which regresses the coefficient of avoidance at the ZIP Code level on each ZIP Code's voting share in 2016. Lastly, while the average coefficients estimated in Table 3 showed greater avoidance of non-Chinese Asian restaurants than Chinese restaurants, we see in Figure 3 that this trend reverses for ZIP Codes with high Trump support. This provides support for Hypothesis 3, that greater Trump support would be associated with greater avoidance of Chinese restaurants.

The result that Chinese restaurant avoidance increased with Trump voting share supports that assignment of pandemic blame had downstream impacts on consumers' food consumption choices. Given that a significant fraction of Asian restaurants in the U.S. serve Chinese food, the finding that Asian restaurants overall also saw a decline in traffic is unsurprising. What is less expected is that non-Chinese Asian restaurants both saw a decline in traffic on average and that this decline increased in areas with a higher Trump voting share. We explore a potential mechanism for this in the next subsection.

\section{Consumer Discrimination as an Underlying Mechanism}

\section{Surveys Show Blame on Asians and Fear of Chinese Food}

We start with a very straightforward question about blame: "Which racial or ethnic group do you believe is most responsible for bringing COVID-19 (aka coronavirus) into the U.S. (if any)?" For the first three waves we had one iteration of the question with six possible answers presented in a randomized order: "Asians", "Blacks", "Latinos", "Whites", "No racial or ethnic group is responsible", and "Don't know". We would expect, if anything, social desirability to motivate people to over-respond "No racial or ethnic group is responsible", but that 


\begin{tabular}{|c|c|c|c|}
\hline \multicolumn{4}{|c|}{ Table 4: Heterogeneity in Effects } \\
\hline & \multicolumn{3}{|c|}{ Dependent variable: } \\
\hline & \multicolumn{3}{|c|}{ Traffic Impact to Restaurant Type } \\
\hline & Asian & Chinese & Non-Chinese Asian \\
\hline Trump 2016 Vote Share & $\begin{array}{c}-0.058^{* * *} \\
(0.011)\end{array}$ & $\begin{array}{c}-0.051^{* * *} \\
(0.012)\end{array}$ & $\begin{array}{c}-0.083^{* * *} \\
(0.014)\end{array}$ \\
\hline Constant & $\begin{array}{c}-0.027^{* * *} \\
(0.005)\end{array}$ & $\begin{array}{c}-0.029^{* * *} \\
(0.006)\end{array}$ & $\begin{array}{l}-0.011 \\
(0.007)\end{array}$ \\
\hline \multicolumn{4}{|l|}{ Controls } \\
\hline Median Household Income & Yes & Yes & Yes \\
\hline College Education & Yes & Yes & Yes \\
\hline Percent Population White & Yes & Yes & Yes \\
\hline Percent Population Asian & Yes & Yes & Yes \\
\hline Observations & 11,773 & 10,910 & 7,723 \\
\hline $\mathrm{R}^{2}$ & 0.002 & 0.002 & 0.004 \\
\hline Adjusted $\mathrm{R}^{2}$ & 0.002 & 0.002 & 0.004 \\
\hline Residual Std. Error & $0.200(\mathrm{df}=11771)$ & $0.208(\mathrm{df}=10908)$ & $0.204(\mathrm{df}=7721)$ \\
\hline \multirow[t]{2}{*}{ F Statistic } & $28.766^{* * *}(\mathrm{df}=1 ; 11771)$ & $19.083^{* * *}(\mathrm{df}=1 ; 10908)$ & $34.523^{* * *}(\mathrm{df}=1 ; 7721)$ \\
\hline & & ${ }^{*} \mathrm{p}$ & $.1{ }^{* *} \mathrm{p}<0.05 ;{ }^{* * *} \mathrm{p}<0.01$ \\
\hline \multicolumn{4}{|c|}{$\begin{array}{l}\text { Notes: Heterogeneity in relative impacts to Asian, Chinese, and non-Chines } \\
\text { Impact coefficients are calculated for each ZIP Code via difference-in-diffe } \\
\text { specification in Table } 3 \text { relative to non-Asian restaurants within the ZIP Co } \\
\text { on the Trump } 2016 \text { vote share within the ZIP Code, controlling for median } \\
\text { college education, and racial demographics within each ZIP Code. The coe } \\
2016 \text { vote share is negative and significant in each case, reinforcing the cor } \\
\text { Trump support and avoidance of Asian restaurants shown in Figure } 3 \text {. }\end{array}$} \\
\hline
\end{tabular}

answer hovers in the low 60's, with a meaningful (but monotonically decreasing) 27\% (Wave 1) to $17 \%$ (Wave 4) reporting "Asians" as the most popular ethnic group blamed. In Wave 4 on April 15, 2021 we randomly assigned half the sample to see a different set of answers to the same question, again in a randomized order: "Chinese", "Japanese", "Italian", "French", "Mexicans", "Greeks", "Indians", "Thai", "Other", "No racial or ethnic group is responsible", and "Don't know". Even at this late date 38\% answered "Chinese". While "No racial or ethnic group is responsible" is the most popular answer under all answer sets and days, a nonnegligible amount of Americans blame Asians, and Chinese in-particular, for bringing COVID- 


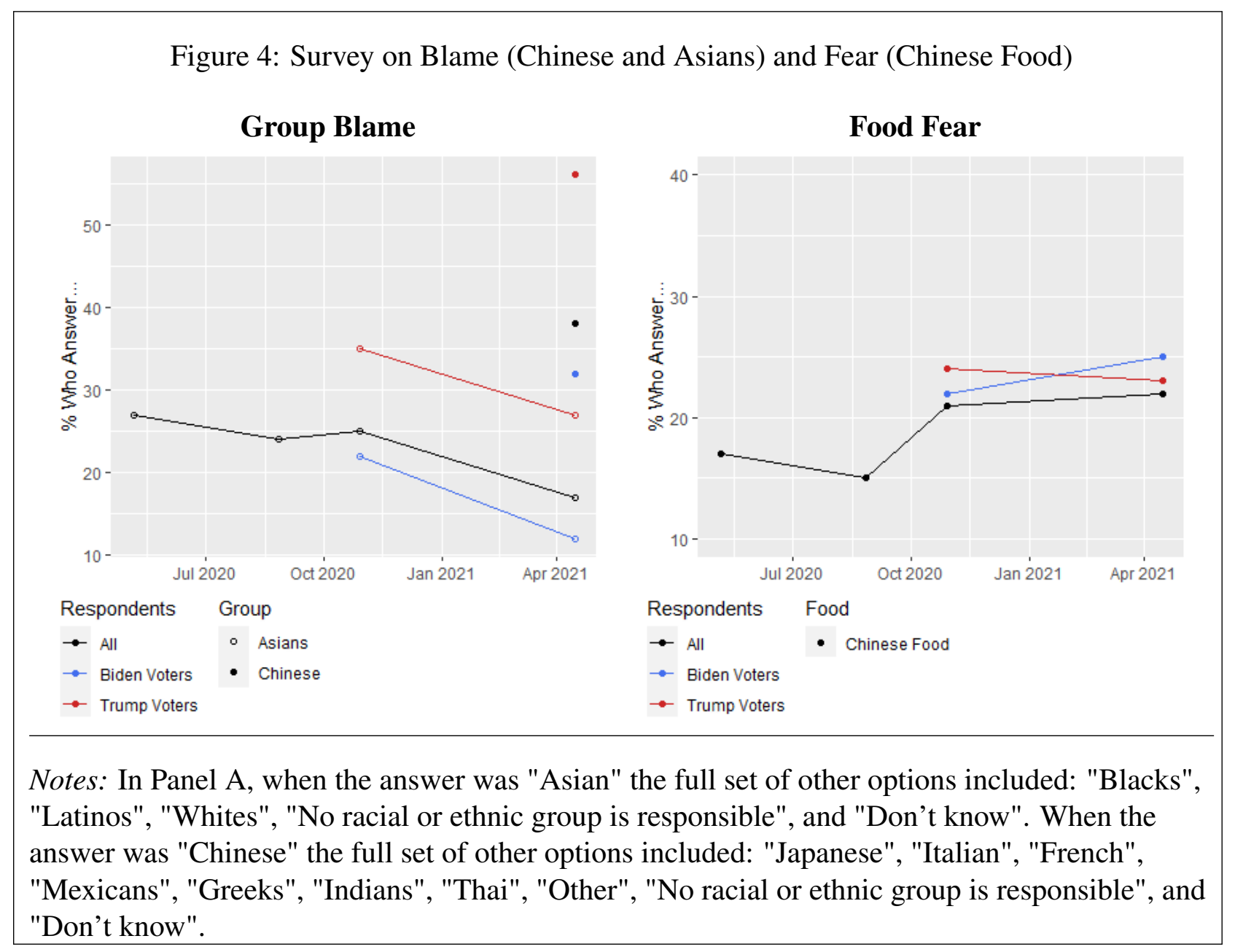

19 into the U.S. The results are visualized in Figure 4.

Trump voters blamed Asians, in particular Chinese, at much higher rates than Biden voters. In the final survey on April 15, 2021 just 12\% of Biden voters said they blame Asians, with $32 \%$ blaming Chinese. But, in the same survey $27 \%$ of Trump voters blamed Asians, and a majority, $56 \%$ blamed Chinese.

We also asked a direct question about fear and risk of contracting COVID-19: "When considering delivery food, ordering which (if any) of the following types of food do you believe presents an increased risk of contracting COVID-19 (aka coronavirus) into the U.S. (if any)?" This question allowed for multiple answers, and "Chinese food" was very consistently the leading answer with between $15 \%$ and $22 \%$. This was between 5 to 9 percentage points higher 


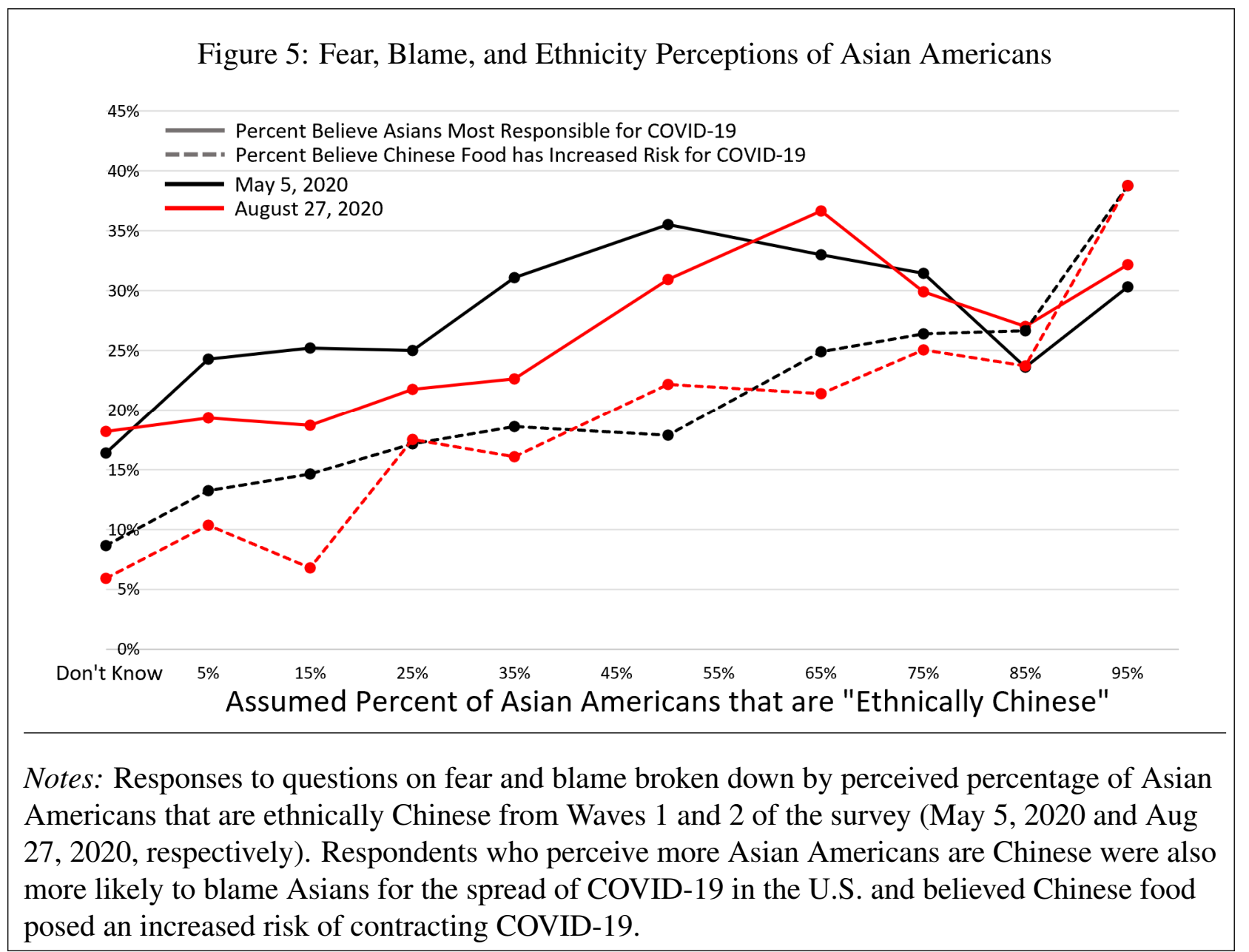

than the next answer. Interestingly, Biden and Trump voters did not show much difference to this fear question, while our restaurant traffic analysis indicated that avoidance of Chinese and more broadly Asian restaurants is strongly correlated with support for Trump. This suggests that blame sentiment may have played a larger role for restaurant avoidance than fear of contracting COVID-19 from Chinese food.

Finally, we looked to examine the interaction between perceptions of Asian homogeneity and directed blame or fear, as illustrated in Figure 5. We asked respondents, "What fraction of Asians in the U.S. do you think are ethnically Chinese?" We note two trends: first, that respondents consistently overestimated the fraction of Asians Americans that were Chinese (mean 
survey response $35 \%$ versus $24 \%$ actual 7 . This is consistent with the predictions of out-group homogeneity bias, where respondents will tend to overestimate the homogeneity of the outgroup. Second, examining respondents who believed that a majority (50\% or more) of Asians in the U.S. were ethnically Chinese, we find this group is also significantly more likely to believe that Chinese food represented an increased risk of contracting COVID-19 (28\% versus $17 \%$ among all respondents, $\mathrm{p}<.01$ ) or that Asians were to blame for the spread of COVID19 (32\% versus $22 \%$ among all respondents, $\mathrm{p}<.01)$. This second trend supports the relationship between perceived homogeneity of Asians as a group and fear and blame directed towards Asian Americans.

\section{Increased Searches Relating to Chinese Food Safety}

To delve further on the question of fear versus discrimination, we examine the search patterns around Chinese restaurants and other restaurants from 2016-2020. Figure 6 shows that searchers exhibited very different search patterns around Chinese restaurants. For regular searches around restaurant safety, we see a large spike in the week immediately following Trump's March 11 address. For Chinese food safety searches, however, the largest spikes came in February and early March 2020, with the largest spike during the week of March 11. These results show that people were thinking about the safety of Chinese restaurants and other restaurants differently during the pandemic.

\section{Confusion Among Asian Restaurants a Potential Mechanism for Spillover Effects}

Following on our mobility analysis, we investigate how anti-China messaging can spillover to a decline in business for non-Chinese Asian restaurants. We specifically examine confusion among Asian restaurants as the potential mechanism, motivated by extant literature on out-

\footnotetext{
${ }^{7}$ https://www.pewresearch.org/fact-tank/2021/04/29/key-facts-about-asian-americans/.
} 
Figure 6: Food Safety Searches
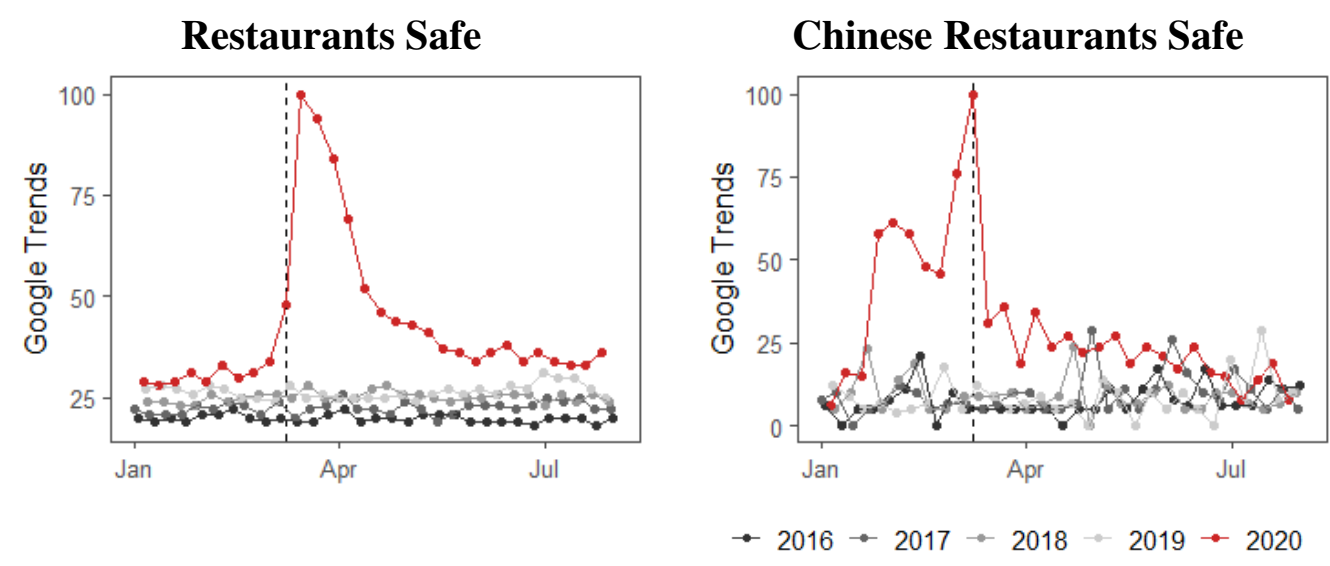

Notes: Google Trends data shows that searches relating to concern about the safety of Chinese food peaked earlier than searches relating to concerns about the safety of restaurants in general.

group homogeneity bias and a history of attacks against Asian Americans where attackers were motivated by hatred against one Asian group yet attacked victims of another Asian group 8 .

We conducted a survey to test this mechanism with 2,000 participants. Each participant was shown a list of 20 ethnic restaurant names (selected from Chinese, Japanese, Korean, Thai, Vietnamese, Indian, Mexican, Italian, and French), randomly selected from real, monoethnic restaurants within the SafeGraph location dataset, and asked to categorize each one by its ethnicity. We find that misidentification is high: $33 \%$ of Asian restaurants are incorrectly labeled by respondents. The most commonly mislabeled Asian restaurants were Korean and Vietnamese, which were incorrectly labeled $52 \%$ and $47 \%$ of the time, respectively. Both of these were most commonly mislabeled as being Chinese, providing strong support for the misclassification mechanism behind Asian restaurant avoidance.

\footnotetext{
${ }^{8}$ Vincent Chin murder 35 years later: History repeating itself?. https://www.freep.com/story/news/2017/06/24/murdervincent-chin-35-years-ago-remembered-asian-americans/420354001/. Retrieved May 6, 2021;

Report: Sam's Club stabbing suspect thought family was 'Chinese infecting people with coronavirus'. https://www.kxan.com/news/crime/report-sams-club-stabbing-suspect-thought-family-was-chinese-infecting-peoplewith-coronavirus/. Retrieved May 6, 2021;

Texas ramen shop still requiring masks hit with anti-Asian graffiti. https://www.nbcnews.com/news/asianamerica/texas-ramen-shop-still-requiring-masks-hit-anti-asian-graffiti-n1261129. Retrieved May 6, 2021.
} 
Figure 7: Asian Restaurant Misidentification Rate by Voting Preferences

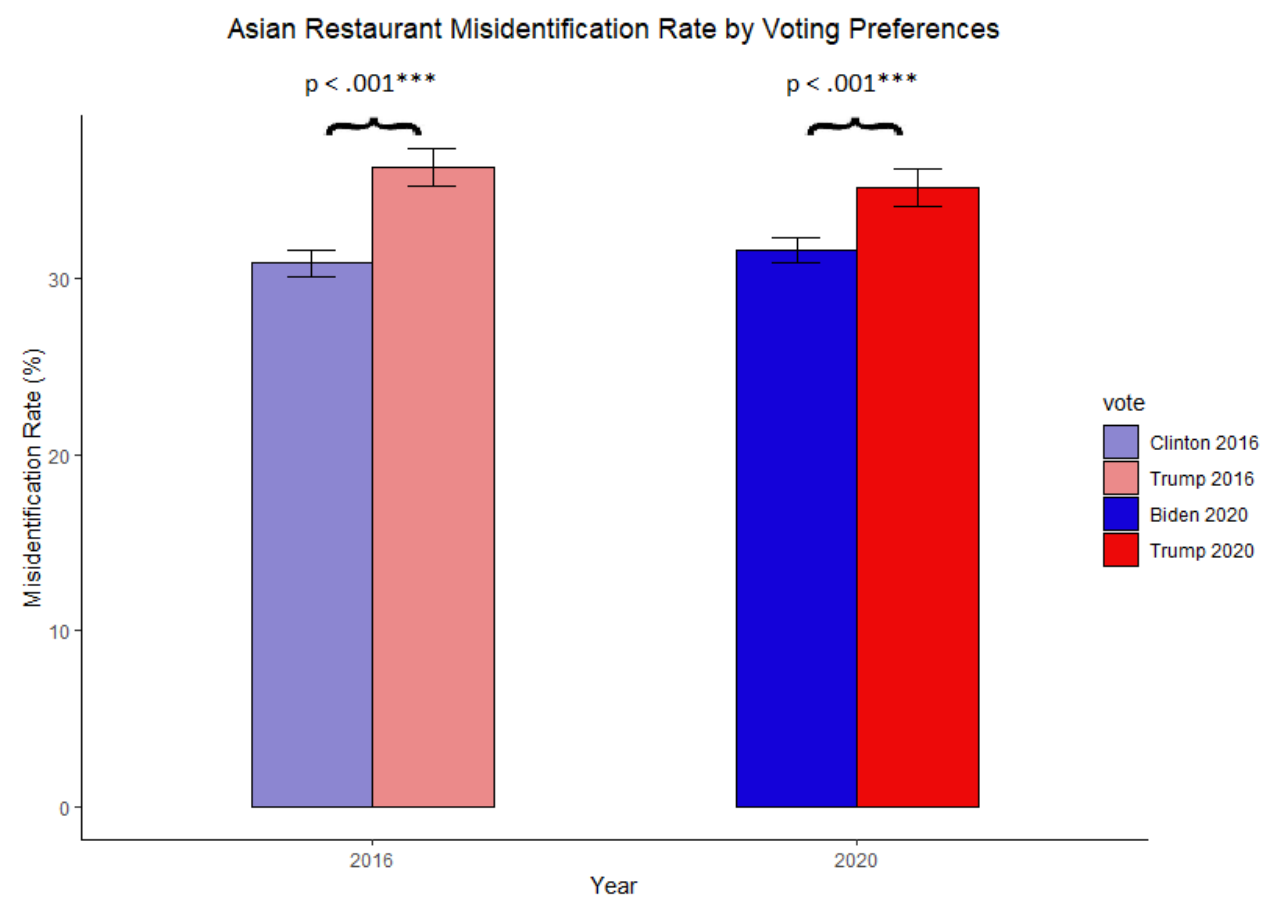

Notes: Misidentification rate of Asian restaurants split based on voting preferences. MTurk survey conducted on 2,000 participants asked to label a randomly selected sample of real, mono-ethnic restaurants from the SafeGraph dataset by ethnic group. p-values shown are results of a two-sided z-score test for difference of proportions.

We also break down correct response rate by participants' 2016 and 2020 voting preferences, as shown in Figure 7. These results indicate that Trump 2016 and 2020 voters were more likely to misidentify Asian restaurants (36.4\% and 35.2\% misidentification, respectively) compared to Clinton 2016 and Biden 2020 voters (30.9\% and 31.6\% misidentification, respectively). Two-proportion $\mathrm{Z}$ tests comparing Trump vs. Clinton voters in 2016 and Trump vs. Biden voters in 2020 indicate these differences in misidentification rate are highly significant $(\mathrm{p}<.001$ for each).

Recalling our other survey results, we noted a significant interaction in that respondents who (falsely) believed that a majority of Asians in the U.S. were Chinese were also more likely to report a fear that Chinese food represented an increased risk of contracting COVID- 
19. We also find that greater Trump support is associated with both increased misclassification of Asian restaurants and greater avoidance of non-Chinese Asian restaurants (Figure 3). Taken together, these results illustrate the linkage between expressions of out-group homogeneity bias (perceived increased homophily or inability to distinguish between out-groups) and Asian restaurant avoidance attitudes and behaviors. This provides strong mechanistic support that some of non-Chinese Asian restaurant avoidance is driven by ethnic misidentification as stated in Hypothesis 4.

\section{Conclusion}

In this paper, we examined the effects of anti-Asian sentiment on consumer discrimination against restaurants associated with Asian Americans. Leveraging and documenting the COVID19 pandemic as an exogenous shock to anti-Asian sentiment, we find a marked and substantial decline in visits to both Chinese and non-Chinese Asian restaurants. In line with partisan cuing theories, we find this effect to be most prominent in areas with more Trump voters. While Trump voters were not more likely to express safety concerns with consumption of Chinese food, they were significantly more likely to attribute blame for pandemic spread to Asians or Chinese. This suggests that anti-Asian sentiment drove restaurant avoidance beyond perceived risk of contracting COVID-19. Finally, we examined a potential driver of spillovers to non-Chinese Asian restaurants in ethnic misidentification. Consistent with our hypothesis, survey responses showed that individuals who incorrectly believed the majority of Asian Americans were Chinese also expressed greater fear of Chinese food, and Trump support correlated with both increased avoidance of non-Chinese Asian restaurants and ethnic misidentification of Asian restaurants.

Given our findings, it is unlikely that legitimate concerns over health from consuming restaurant food explain the disproportionate drop in visits for Chinese restaurants as well as 
non-Chinese Asian restaurants. Rather, it is likely that anti-China sentiment - regardless of whether it was driven by fear or anger - triggered by COVID-19 and reinforced by U.S. political rhetoric played a significant role in consumer discrimination against Asian-owned restaurants.

It should be noted that concerns about rising anti-Asian discrimination extend far beyond the consequences of the COVID-19 pandemic. Asian Americans have made up the plurality of immigrants to the U.S. since 2008 (Budiman 2020). Historically, the large increases in California's Chinese immigrant population during the 19th century were swiftly followed by a sharp increase in anti-Asian sentiment and discrimination, which persisted even after legislation stopped the flow of new immigrants from Asia (Liu 2015; Chiu and Kirk 2014). In addition to this historical example, recent research (Cikara, Fouka and Tabellini 2021) has found that as minority groups increase in rank in terms of their relative size (e.g., to largest minority within a community), negative attitudes and violence toward these minority groups increase as well. Together with our own findings, these examples suggest that the U.S. may be entering a longer period of increased anti-Asian sentiment, which makes understanding the effects of discrimination against this group even more important.

A number of limitations of this research derive from the fact that the onset of COVID-19 was a single, unprecedented shock to public health and the global economy. For example, we cannot entirely disentangle the relative role of political leaders' anti-Asian rhetoric from endogenous anti-Asian sentiment arising from the public health threat itself. History has repeatedly shown that blaming marginalized groups for public health crises is sadly quite common (Perry and Donini-Lenhoff 2010; Keusch, Wilentz and Kleinman 2006). For example, Irish immigrants were blamed as the bearers of cholera, and Jewish immigrants were blamed for tuberculosis (Kraut 2010). More recently, African and Chinese cultural habits were also blamed for the outbreaks of Ebola and SARS (Kapiriri and Ross 2020), and Latinos were blamed for the spread of H1N1 (McCauley, Minsky and Viswanath 2013). It is possible that anti-Asian 
sentiment would have arisen even absent public officials' statements targeting Asians, or that politicians' statements are reflective of constituent beliefs rather than formative. However, the long history of stigmatization, discrimination, and violence toward minority groups following disease outbreaks should put greater onus on public officials to avoid such statements due to exactly these risks to minority communities. While we cannot reliably create a counterfactual world where COVID-19 was not followed by anti-China rhetoric by the U.S. political leaders, future research might further examine the relative importance of different triggers for antiAsian sentiment, discrimination, and behavior.

\section{References}

Acquisti, Alessandro and Christina Fong. 2020. "An experiment in hiring discrimination via online social networks." Management Science 66(3):1005-1024.

Alicke, Mark D. 2000. "Culpable control and the psychology of blame." Psychological bulletin 126(4):556.

Bassanini, Andrea and Anne Saint-Martin. 2008. "The price of prejudice: Labour market discrimination on the grounds of gender and ethnicity.".

Bertrand, Marianne and Sendhil Mullainathan. 2004. "Are Emily and Greg more employable than Lakisha and Jamal? A field experiment on labor market discrimination." American economic review 94(4):991-1013.

Borah, Abhishek and Gerard J Tellis. 2016. "Halo (spillover) effects in social media: do product recalls of one brand hurt or help rival brands?" Journal of Marketing Research 53(2):143-160.

Borjas, George J and Stephen G Bronars. 1989. "Consumer discrimination and selfemployment." Journal of political economy 97(3):581-605. 
Broyles, Philip and Weston Fenner. 2010. "Race, human capital, and wage discrimination in STEM professions in the United States." International Journal of Sociology and Social Policy

Budhwani, Henna and Ruoyan Sun. 2020. "Creating COVID-19 stigma by referencing the novel coronavirus as the "Chinese virus" on Twitter: quantitative analysis of social media data.” Journal of Medical Internet Research 22(5):e19301.

Budiman, Abby. 2020. "Key findings about U.S. immigrants.".

Bullock, John G. 2020. Party cues. In The Oxford handbook of electoral persuasion. Oxford University Press, USA p. 129.

Bursztyn, Leonardo, Thomas Chaney, Tarek Alexander Hassan and Aakaash Rao. 2021. "The Immigrant Next Door: Exposure, Prejudice, and Altruism.” National Bureau of Economic Research No. w28448.

Campbell, Mary E and Lisa Troyer. 2007. "The implications of racial misclassification by observers." American Sociological Review 72(5):750-765.

Chae, David H, Sean Clouston, Mark L Hatzenbuehler, Michael R Kramer, Hannah LF Cooper, Sacoby M Wilson, Seth I Stephens-Davidowitz, Robert S Gold and Bruce G Link. 2015. "Association between an internet-based measure of area racism and black mortality." PloS one 10(4):e0122963.

Chance, June and Alvin Goldstein. 1981. "Depth of processing in response to own-and otherrace faces." Personality and Social Psychology Bulletin 7.3:475-480.

Chandrasekhar, Charu A. 2003. "Flying while brown: Federal civil rights remedies to post9/11 airline racial profiling of South Asians.” Asian Law Journal 10:215.

Chavez, Koji. 2021. "Penalized for Personality: A Case Study of Asian-Origin Disadvantage at the Point of Hire." Sociology of Race and Ethnicity 7(2):226-246. 
Chiu, Herman B and Andrew Taylor Kirk. 2014. ""Unlimited American Power": How Four California Newspapers Covered Chinese Labor and the Building of the Transcontinental Railroad, 1865-1869.” American Journalism 31(4):507-524.

Cikara, Mina, Vasiliki Fouka and Marco Tabellini. 2021. "Hate crime increases with minoritized group rank.”.

Denson, Thomas F, Brian Lickel, Mathew Curtis, Douglas M Stenstrom and Daniel R Ames. 2006. "The roles of entitativity and essentiality in judgments of collective responsibility." Group Processes \& Intergroup Relations 9(1):43-61.

Dhanani, Lindsay Y and Berkeley Franz. 2021. "Why public health framing matters: An experimental study of the effects of COVID-19 framing on prejudice and xenophobia in the United States.” Social science \& medicine 269:113572.

Druckman, James N. 2001. "The implications of framing effects for citizen competence." Political behavior 23(3):225-256.

Dustmann, Christian and Nikolaos Theodoropoulos. 2010. "Ethnic minority immigrants and their children in Britain.” Oxford Economic Papers 62(2):209-233.

Fairlie, Robert W. 1999. "The absence of the African-American owned business: An analysis of the dynamics of self-employment." Journal of Labor Economics 17(1):80-108.

Ghazaryan, Armine. 2019. "The impact of labour market discrimination on welfare dependency of second generation immigrants in the UK.".

Gover, Angela R, Shannon B Harper and Lynn Langton. 2020. "Anti-Asian hate crime during the COVID-19 pandemic: Exploring the reproduction of inequality." American Journal of Criminal Justice 45(4):647-667.

Graham, Matthew H and Shikhar Singh. 2021. "Partisan Selectivity in Blame Attribution: Evidence from the COVID-19 Pandemic." SocArXiv. March 5. 
Green, Eva GT, Franciska Krings, Christian Staerklé, Adrian Bangerter, Alain Clémence, Pascal Wagner-Egger and Thierry Bornand. 2010. "Keeping the vermin out: Perceived disease threat and ideological orientations as predictors of exclusionary immigration attitudes." Journal of Community \& Applied Social Psychology 20(4):299-316.

Hart, Herbert Lionel Adolphus and Tony Honoré. 1985. Causation in the Law. OUP Oxford.

Holzer, Harry J and Keith R Ihlanfeldt. 1998. "Customer discrimination and employment outcomes for minority workers." The Quarterly Journal of Economics 113(3):835-867.

Hswen, Yulin, Xiang Xu, Anna Hing, Jared B Hawkins, John S Brownstein and Gilbert C Gee. 2021. “Association of â\# Covid19â Versus â\# Chinesevirusâ with Anti-Asian Sentiments on Twitter: March 9-23, 2020.” American Journal of Public Health 111(5):956-964.

Jedwab, Remi, Noel D Johnson and Mark Koyama. 2019. "Negative shocks and mass persecutions: evidence from the Black Death.” Journal of Economic Growth 24(4):345-395.

Johnson, Paula. 1996. “The Social Construction of Identity in Criminal Cases: Cinema Verite and the Pedagogy of Vincent Chin.” Michigan Journal of Race and Law 1:347.

Kapiriri, Lydia and Alison Ross. 2020. "The politics of disease epidemics: a comparative analysis of the SARS, zika, and Ebola outbreaks." Global Social Welfare 7(1):33-45.

Keusch, Gerald, Joan Wilentz and Arthur Kleinman. 2006. "Stigma and global health: developing a research agenda." The Lancet 367:525-527.

Kraut, Alan M. 1995. Silent travelers: Germs, genes, and the immigrant menace. JHU Press.

Kraut, Alan M. 2010. "Immigration, ethnicity, and the pandemic." Public health reports 125(3_suppl):123-133.

Krings, Franciska, Eva T Green, Adrian Bangerter, Christian Staerklé, Alain Clémence, Pascal Wagner-Egger and Thierry Bornand. 2012. "Preventing Contagion With Avian Influenza: 
Disease Salience, Attitudes Toward Foreigners, and Avoidance Beliefs 1." Journal of Applied Social Psychology 42(6):1451-1466.

Krosch, Amy R., Leslie Berntsen, David M. Amodio, John T. Jost and Jay J. Van Bavel. 2013. "On the ideology of hypodescent: Political conservatism predicts categorization of racially ambiguous faces as Black.” Journal of Experimental Social Psychology 49(6):1196-1203.

Krupenkin, Masha, Kai Zhu, Dylan Walker and David M Rothschild. 2021. If a Tree Falls in the Forest: COVID-19, Media Choices, and Presidential Agenda Setting. Technical report.

Kuppuswamy, Venkat and Peter Younkin. 2020. "Testing the theory of consumer discrimination as an explanation for the lack of minority hiring in hollywood films." Management Science 66(3):1227-1247.

Lebrecht, Sophie, Lara Pierce, Michael Tarr and James Tanaka. 2009. "Perceptual other-race training reduces implicit racial bias." PloS one 4.1:e4215.

Lee, Suyeon and Sara F Waters. 2020. "Asians and Asian Americansâ experiences of racial discrimination during the COVID-19 pandemic: Impacts on health outcomes and the buffering role of social support." Stigma and Health .

Lenz, Gabriel S. 2013. Follow the leader?: how voters respond to politicians' policies and performance. University of Chicago Press.

Li, Yao and Harvey L Nicholson Jr. 2021. "When "model minorities" become "yellow peril" - Othering and the racialization of Asian Americans in the COVID-19 pandemic." Sociology Compass 15(2):e12849.

Lickel, Brian, Norman Miller, Douglas M Stenstrom, Thomas F Denson and Toni Schmader. 2006. "Vicarious retribution: The role of collective blame in intergroup aggression." Personality and social psychology review 10(4):372-390. 
Liu, Feng, Xin Liao and Cuiqin Ming. 2020. "Prejudice, does it exist or not? Consumer price discrimination in minority entrepreneurship." Frontiers in Psychology 11.

Liu, Haiming. 2015. From Canton Restaurant to Panda Express. Rutgers University Press.

Markel, Howard and Alexandra Minna Stern. 1999. "Which face? Whose nation? Immigration, public health, and the construction of disease at America's ports and borders, 1891-1928." American Behavioral Scientist 42(9):1314-1331.

Mason, Patrick L, Cecelia Conrad, John Whitehead, Patrick Mason and James Stewart. 2005. "Persistent racial discrimination in the labor market." African Americans in the US economy pp. 141-50.

Masters-Waage, Theodore C, Nilotpal Jha and Jochen Reb. 2020. "COVID-19, Coronavirus, Wuhan Virus, or China Virus? Understanding How to âDo No Harmâ When Naming an Infectious Disease.” Frontiers in Psychology 11:3369.

McCauley, Michael, Sara Minsky and Kasisomayajula Viswanath. 2013. "The H1N1 pandemic: media frames, stigmatization and coping." BMC Public Health 13.1:1-16.

Milosh, Maria, Marcus Painter, Konstantin Sonin, David Van Dijcke and Austin L Wright. 2020. "Unmasking partisanship: Polarization undermines public response to collective risk.".

Miro-Llinares, F and JJ Rodriguez-Sala. 2016. "Cyber hate speech on twitter: Analyzing disruptive events from social media to build a violent communication and hate speech taxonomy." International Journal of Design \& Nature and Ecodynamics 11(3):406-415.

Mosby, Ian. 2009. “'That Won-Ton Soup Headache': The Chinese Restaurant Syndrome, MSG and the Making of American Food, 1968-1980.” Social History of Medicine 22(1):133-151.

Mullen, Brian and Li-Tze Hu. 1989. "Perceptions of ingroup and outgroup variability: A metaanalytic integration." Basic and Applied Social Psychology 10.3:233-252. 
Müller, Karsten and Carlo Schwarz. 2021. "Fanning the flames of hate: Social media and hate crime." Journal of the European Economic Association 19(4):2131-2167.

Ostrom, Thomas M., Sandra L. Carpenter, Constantine Sedikides and Fan Li. 1993. "Differential processing of in-group and out-group information." Journal of Personality and Social Psychology 64(1):21-34.

Pager, Devah. 2003. "The mark of a criminal record.” American journal of sociology 108(5):937-975.

Paruchuri, Srikanth and Vilmos F Misangyi. 2015. "Investor perceptions of financial misconduct: The heterogeneous contamination of bystander firms." Academy of Management Journal 58(1):169-194.

Pei, Xin and Deval Mehta. 2020. “\# Coronavirus or\# Chinesevirus?!: Understanding the negative sentiment reflected in Tweets with racist hashtags across the development of COVID19." arXiv preprint arXiv:2005.08224 .

Perry, Phil and Fred Donini-Lenhoff. 2010. "Stigmatization complicates infectious disease management." AMA Journal of Ethics 12.3:225-230.

Prosser, William and J Wade. 1971. "Cases and Materials on the Law of Torts.”.

Quattrone, George A and Edward E Jones. 1980. "The perception of variability within ingroups and out-groups: Implications for the law of small numbers." Journal of personality and social psychology 38(1):141.

Quillian, Lincoln, Devah Pager, Ole Hexel and Arnfinn H Midtbøen. 2017. "Meta-analysis of field experiments shows no change in racial discrimination in hiring over time." Proceedings of the National Academy of Sciences 114(41):10870-10875.

Quillian, Lincoln, John J Lee and Brandon Honoré. 2020. "Racial discrimination in the US 
housing and mortgage lending markets: a quantitative review of trends, 1976-2016." Race and Social Problems 12(1):13-28.

Reny, Tyler T and Matt A Barreto. 2020. "Xenophobia in the time of pandemic: othering, antiAsian attitudes, and COVID-19.” Politics, Groups, and Identities pp. 1-24.

Stenstrom, Douglas M, Brian Lickel, Thomas F Denson and Norman Miller. 2008. "The roles of ingroup identification and outgroup entitativity in intergroup retribution." Personality and Social Psychology Bulletin 34(11):1570-1582.

Stephens-Davidowitz, Seth. 2014. "The cost of racial animus on a black candidate: Evidence using Google search data." Journal of Public Economics 118:26-40.

Stephens-Dougan, LaFleur. 2020. Race to the Bottom: How Racial Appeals Work in American Politics. University of Chicago Press.

Tessler, Hannah, Meera Choi and Grace Kao. 2020. “The anxiety of being Asian American: Hate crimes and negative biases during the COVID-19 pandemic." American Journal of Criminal Justice 45(4):636-646.

Trump, Rebecca K and Kevin P Newman. 2017. "When do unethical brand perceptions spill over to competitors?" Marketing Letters 28(2):219-230.

Wahlstedt, Amanda, Elizabeth Bradley, Juan Castillo and Kate Gardner Burt. 2021. "MSG Is A-OK: Exploring the Xenophobic History of and Best Practices for Consuming Monosodium Glutamate." Journal of the Academy of Nutrition and Dietetics .

Weisel, Ori. 2021. "Vaccination as a social contract: The case of COVID-19 and US political partisanship." Proceedings of the National Academy of Sciences 118(13).

White, Richard. 2011. Railroaded: the transcontinentals and the making of modern America. WW Norton \& Company. 
World Health Organization. 2015. "WHO issues best practices for naming new human infectious diseases." https://www.who.int/news/item/ 08-05-2015-who-issues-best-practices-for-naming-new-human-infectious-diseases. Accessed: 2021-07-16.

Younkin, Peter and Venkat Kuppuswamy. 2018. "The colorblind crowd? Founder race and performance in crowdfunding." Management Science 64(7):3269-3287.

Zebrowitz, Leslie, Benjamin White and Kristin Wieneke. 2008. "Mere exposure and racial prejudice: Exposure to other-race faces increases liking for strangers of that race." Social Cognition 26.3:259-275.

Ziems, Caleb, Bing He, Sandeep Soni and Srijan Kumar. 2020. "Racism is a virus: Antiasian hate and counterhate in social media during the covid-19 crisis." arXiv preprint arXiv:2005.12423 . 


\section{Supplementary Files}

This is a list of supplementary files associated with this preprint. Click to download.

- COVIDDiscriminationAppendix.pdf 